Original Article

\title{
A quantitative assessment of the mechanical effects on the lumbar spine and the effects on straight leg raising and lumbar flexion of segmental sustained rotation
}

\author{
Yoetsu Ogata ${ }^{1)^{*}}$, Masayoshi Kamijo, PhD²), Masaaki Hanaoka, PhD ${ }^{1)}$ \\ 1) Koriyama Institute of Health Sciences: 2-9-3 Zukei, Koriyama, Fukushima 963-8834, Japan \\ 2) Course of Kansei Engineering, Faculty of Textile Science and Technology, Shinshu University, Japan
}

\begin{abstract}
Purpose] This study were to examine the strength and relative direction of the applied force from lumbar segmental sustained rotation (LSSR) on the lumbar spinous process, and to clarify the effects of LSSR on straight leg raising (SLR) and lumbar flexion (LF). [Subjects] 18 pain-free healthy adults volunteered for this study. [Methods] Applied force and direction were measured between the L5-S1 segments using tri-axial pressure sensors. Subjects participated in 3 trials. Subjects underwent localized right rotation, held for 10 seconds, of the L5 in relation to the S1. Sham group subjects followed LSSR group protocols; however L5-S1 rotation was absent. Control subjects rested on a plinth. SLR and LF were measured pre and post-trial. [Results] Outcome data for LSSR forces were as follows; $\mathrm{x}(0.06 \mathrm{~N}( \pm 0.29))$, y $(-5.26 \mathrm{~N}( \pm 0.01)), \mathrm{z}(6.16 \mathrm{~N}( \pm 1.33))$, and resultant vector magnitude $(8.19 \mathrm{~N}( \pm 1.12))$. LSSR relative direction results were as follows: $\mathrm{x}$-axis angle, $89.6^{\circ}( \pm 1.5)$; y-axis, $130.9^{\circ}( \pm 5.6)$; and Z-axis, $41.6^{\circ}( \pm 4.7)$. The LSSR group's LF and SLR were significantly increased compared with those of the sham and control groups. [Conclusion] The identified resultant vector magnitude was $8.19 \mathrm{~N}$, less than other techniques. LSSR effectively improves LF and bilateral SLR.

Key words: Tri-axial force measurement system, Relative direction and force, Lumbar segmental sustained rotation
\end{abstract}

(This article was submitted Dec. 17, 2015, and was accepted Jan. 14, 2016)

\section{INTRODUCTION}

Lumbar rotation techniques are commonly used for relieving unilateral signs and symptoms and restoring the pain-free range of motion ${ }^{1-6}$. Maitland ${ }^{1)}$ emphasized that the rotation technique is the most valuable and often the first technique used. However, the mechanical effects of the technique on the lumbar structures have not yet been clearly understood ${ }^{5,7-8)}$.

Rotation techniques can be divided into three types: sustained rotation, cyclic oscillatory rotation, and rotational manipulation $^{1)}$. Physiotherapists use all three treatment techniques while chiropractors and osteopaths mainly use the rotational manipulation techniques ${ }^{9-11)}$. The sustained rotation technique is often used in the treatment of unilateral signs and symptoms, whether the pain is in the local lumbar area or referred to the $\operatorname{leg}^{12}$. It has been suggested that this is perhaps the most valuable technique for patients with symptoms such as a unilateral referred pain, and with suspected nerve root problems ${ }^{1-3,13,14)}$. However, there is no well-designed study to support this suggestion.

Passive oscillatory movements are used for the purpose of treating unilateral back and leg pain, and restoring the painless range of motion ${ }^{3,15-18)}$. Twomey and Taylor ${ }^{19)}$ explain the possible effects of the cyclic oscillation techniques in terms of the promotion of synovial fluid flow through the articular cartilage and disc, and the stretching of the ligaments surrounding the joints, muscles and neuromeningeal tissues. The sustained or cyclic oscillatory rotation technique is usually used as a

*Corresponding author. Yoetsu Ogata (E-mail: y-ogata@k-tohto.ac.jp)

(C)2016 The Society of Physical Therapy Science. Published by IPEC Inc.

This is an open-access article distributed under the terms of the Creative Commons Attribution Non-Commercial No Derivatives (by-nc-nd) License $<$ http://creativecommons.org/licenses/by-nc-nd/4.0/>. 
generalized rotation technique rather than a localized rotation technique ${ }^{5,20)}$. It can be assumed that the lumbar segmental sustained rotation (LSSR) technique would be much more effective than the lumbar general rotation technique as most of the signs and symptoms arise from the segmental level ${ }^{1)}$. The rotational manipulative technique is commonly used for patients with unilateral signs and symptoms in order to reduce pain and increase the range of movement ${ }^{21)}$. Particular advantages of these variations in technique require further investigation ${ }^{22)}$.

At present, the absence of a clear rationale and mechanistic hypothesis make treatment a matter of trial and error. Therefore, the mechanical effects of the treatment of the lumbar spine structures with these types of rotational techniques should be made clear and evaluated critically. Patients with lower back pain who suffer from nerve root or intervertebral disc problems often experience reduced straight leg raising (SLR) and lumbar flexion (LF). Previous studies reported that lumbar general rotation techniques improved SLR and LF, therefore LSSR may be much more effective for improving SLR and LF ${ }^{1,5,23)}$.

There have been no studies with respect to the measurement of the direction of the applied force and strength of LSSR ${ }^{5,7)}$. There have also been no studies regarding the effects of LSSR on SLR and LF. The primary purpose of this study was to examine the relative direction of the x-axis, $y$-axis, and z-axis, and the strength of the applied force from LSSR on the lumbar spinous process, and to identify the safety and adaptation of the LSSR as a treatment technique. The secondly purpose of this study was to clarify the effectiveness of the LSSR technique on SLR and LF.

\section{SUBJECTS AND METHODS}

\section{Subjects}

Eighteen pain-free healthy volunteer subjects ( 9 male, 9 female, aged 21-30 years) were recruited. Subjects' mean age was 22 years, height $( \pm \mathrm{SD})$ was $163.9 \mathrm{~cm}( \pm 10.7 \mathrm{~cm})$, mass was $64.3 \mathrm{~kg}( \pm 18.4 \mathrm{~kg})$, and body mass index was $23.6 \mathrm{~kg} /$ $\mathrm{m}^{2}\left( \pm 4.7 \mathrm{~kg} / \mathrm{m}^{2}\right)$. Subjects had no systemic diseases, serious neurological or musculoskeletal illness or injury prior to the investigation, and no incidence of back or leg pain in the 12 months prior to the commencement of the study. None of the subjects used medication at the time of the investigation. Participants in this study provided informed written consent. Ethical approval was obtained from the Koriyama Institute of Health Sciences ethics committee (Approved Number: R1007).

\section{Methods}

An intra-rater reliability test was conducted prior to the study. A manipulative physiotherapist with 28 years clinical experience tested five male subjects (mean age 21) five times each. Then the main study was conducted by the physiotherapist with 18 subjects. The subjects performed the following 3 trials randomly, and the same subjects participated in all 3 trials: (1) LSSR group, (2) lumbar general rotation (sham group), (3) and rest (control group). The trial order was randomized, and each test was conducted 5 days apart.

Direction and magnitude of applied forces on the S1 spinous process were measured by a Tri-axial force measurement system (USL06-H5-500N, Tec Gihan Co., Ltd., Japan) (Fig. 1). A 30×30×1 mm rubber pad was placed between the skin and the pressure sensor in order to protect the skin from the hard metal of the pressure sensor. The range of measuring error is less than $1 \%$ of the full scale and output characteristics are type C (linear). SLR was measured using a digital level clinometer (MJ-1, Sato Shoji (Co., Ltd.), Japan. The bending forward motion (LF) while standing on a box was measured using a tape measure.

The study was conducted to measure applied forces 3-dimensionally in the lumbar region between the L5-S1 segment using a tri-axial pressure sensor. The participant was asked to lie on their left side, straighten the left leg, and flex both the right knee and hip to about $45^{\circ}$ of flexion. The anterior part of the right foot was hooked to the posterior part of the left knee in order to affect the weight hanging over the side of the plinth. The examiner stood in front of the patient. The tip of the examiner's left index finger hooked and pulled up at the S1 spinous process, and the right thumb pushed down at L5 spinous process. The participant was rotated to the right, and held for 10 seconds at the end of trunk rotation. The tri-axial pressure sensor was applied underneath the S1 spinous process by the left index finger. Then both the direction and the magnitude of the applied force on the S1 spinous process were measured (Fig. 2).

The intra-rater reliability test was conducted with 5 subjects, each measured 5 times repeatedly prior to the start of the study. The resultant vector, angles to the $x$-axis, angles to the $y$-axis and angles to the $z$-axis were measured. In general, the angle $\theta$ between $\mathbf{A}$ and $\mathbf{B}$ of 2 vectors was calculated using the following formula:

Where $\mathbf{A}=\left(A_{x}, A_{y}, A_{z}\right), \mathbf{B}=\left(B_{x}, B_{y}, B_{z}\right)$, the resultant formula is:

$$
\begin{aligned}
(\mathbf{A}, \mathbf{B}) & =|\mathbf{A} \| \mathbf{B}| \cos \theta \\
& =A_{x} B_{x}+A_{y} B_{y+} A_{z} B_{z} \\
\cos \theta & =\left(A_{x} B_{x}+A_{y} B_{y}+A_{z} B_{z}\right) /(|\mathbf{A} \| \mathbf{B}|)=\alpha \\
\theta & =\cos ^{-1} \alpha
\end{aligned}
$$



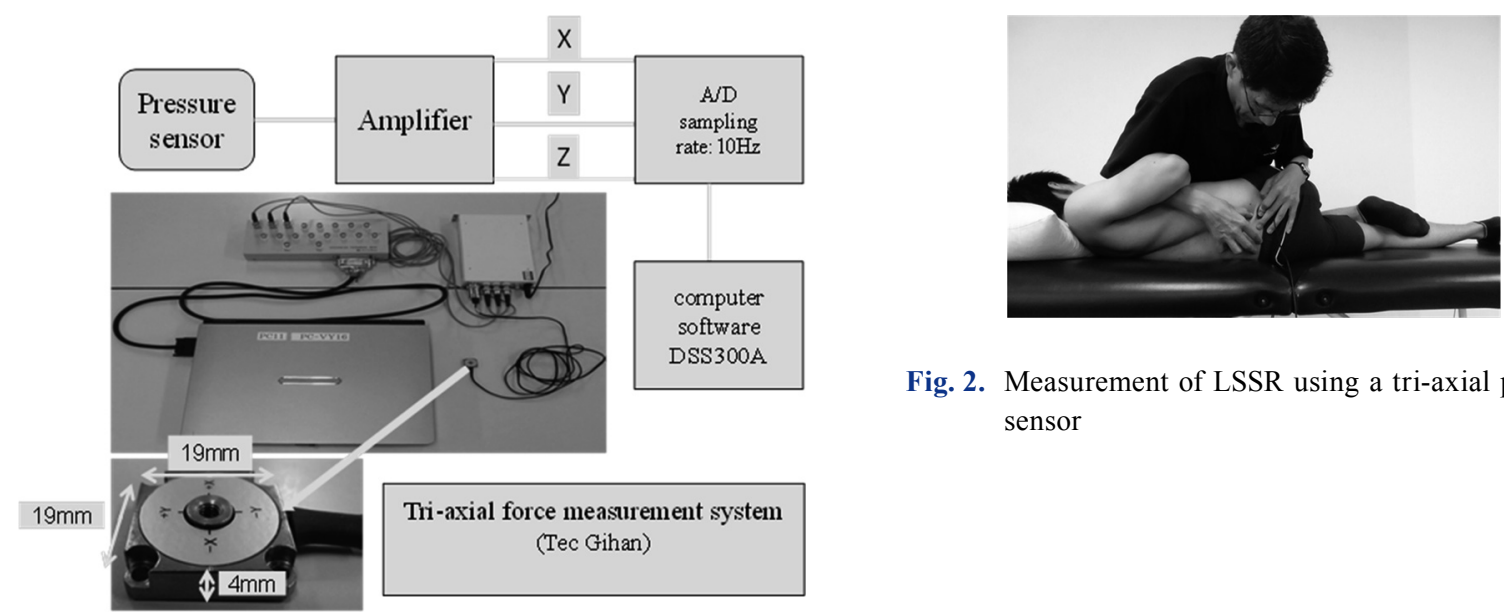

Fig. 2. Measurement of LSSR using a tri-axial pressure sensor

Fig. 1. Tri-axial force measurement system

Note, that $(\mathbf{A}, \mathbf{B})$ is an inner product of $\mathbf{A}$ and $\mathbf{B}$, and they are $|\mathbf{A}|=\sqrt{A_{x}^{2}+A_{y}^{2}+A_{z}^{2}},|\mathbf{B}|=\sqrt{B_{x}^{2}+B_{y}^{2}+B_{z}^{2}}$. Where, $\mathbf{A}=\mathbf{V}=$ $\left(V_{x}, V_{y}, V_{z}\right), \mathbf{B}=(1,0,0)$; the $\theta$ was the angle $\theta_{x}$ derived from the resultant vector $(\mathbf{V})$ and the $x$ - axis.

Therefore, $\cos \theta_{x}=\left(V_{x} \times 1+V_{y} \times 0+V_{z} \times 0\right) /(|\mathbf{V}| \times 1)=V_{x} / \sqrt{V_{x}^{2}+V_{y}^{2}+V_{z}^{2}}=\alpha_{x}$

$$
\theta_{x}=\cos ^{-1} \alpha_{x}
$$

The angle $\theta_{y}$ was derived from the resultant vector $(\mathbf{V})$ and the $y$-axis, and the angle $\theta_{z}$ was derived from the resultant vector $(\mathbf{V})$ and the $z$-axis, which were obtained in a similar fashion as above, with $y$ and $z$ substituting for $x$.

After the intra-rater reliability test had concluded, the main study was performed and the participant was asked to lie left side down on a standard treatment couch. An examiner palpated and found the L5 and S1 spinous process. Then the subject's upper trunk was rotated to the right and the pelvis rotated to the left by the examiner. At the end of the range of the trunk rotation, segmental rotation was applied to press down on the L5 spinous process with the examiner's right thumb and to pull up from underneath the S1 spinous process with the examiner's left index finger and held for 10 seconds (Fig. 2). Before and after this rotation, each subject's SLR and LF were measured on both sides. SLR was measured with a digital level goniometer. The SLR angle was identified as the angle reached when the subject started to feel pain (P1) ${ }^{24)}$. The LF was measured by a tape measure while the subject was standing on a stool. The subject bent forward as if to touch their toes and the distance that they were able to reach was recorded. If they could not reach their toes the figure was recorded as a minus $(\mathrm{cm})$ and if they could reach past their toes it was recorded as a plus $(\mathrm{cm})$. The measuring tape was attached from the stool to the floor perpendicularly. The sham group participants were placed as in the LSSR position for 10 seconds; however, the segmental rotation was not applied (general rotation). The control group participants rested while lying on a plinth and bilateral SLRs were examined twice in order to eliminate any repetitive effects. Bilateral SLRs and LF were measured pre and post-trial twice and the average of the data were collected.

Intra-class correlation-coefficients (ICCs) were calculated to clarify intra-rater consistency. Descriptive statistics were used to describe average force and vectors. A Wilcoxon signed-rank test was used to identify differences between pre and post LSSR in ipsilateral SLR, contralateral SLR, and LF. Comparisons between groups were made by one-way analysis of variance (ANOVA), and Bonferroni post hoc group comparisons ( $\alpha=0.05$ level of significance) were used to clarify LF in the LSSR and the sham groups, and bilateral SLRs in the 3 groups. The SPSS for Windows ver. 21 was used for data analysis.

\section{RESULTS}

The intra-rater reliability of the $\mathrm{x}$-axis (sagittal) force was $(\operatorname{ICC}(1.5)=0.188)$, the $y$-axis (horizontal) force was (ICC (1.5) $=0.875)$, the $\mathrm{z}$-axis (perpendicular) force was $(\operatorname{ICC}(1.5)=0.856)$, and the magnitude of resultant vector was $($ ICC $(1.5)=$ 0.877). Only the $x$-axis force was identified as low intra-rater reliability, however high reliability was identified in the $y$-axis and $\mathrm{z}$-axis force, and the magnitude of resultant vector.

A positive direction of the $\mathrm{x}$-axis was defined as a downward direction. Similarly, the positive direction of the y-axis was a cephalad direction, and a ventral direction was the positive direction of the z-axis (Fig. 3). The relative direction of the magnitude of resultant vector was calculated by using the previously mentioned formula to derive an arc cosine. As a result, the angle from the $\mathrm{x}$-axis to the vector was $89.6^{\circ}\left( \pm 1.5^{\circ}\right)$, the angle from the $y$-axis to the vector was $130.9^{\circ}\left( \pm 5.6^{\circ}\right)$, and the angle from the $\mathrm{z}$-axis to the vector was $41.6^{\circ}\left( \pm 4.7^{\circ}\right)$. 


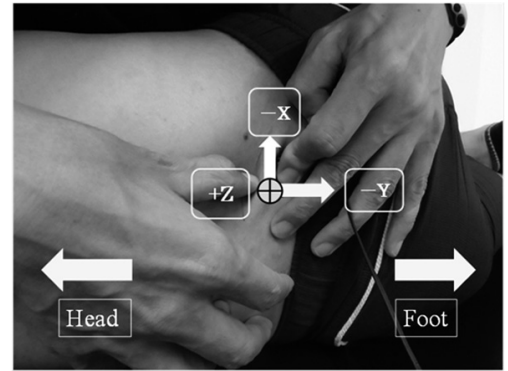

Fig. 3. A positive direction of the $x$-axis (inferior), $y$-axis (cephalad) and z-axis (ventral)

Table 2. Changes in contralateral SLR (degree)

\begin{tabular}{lcl}
\hline & \multicolumn{1}{c}{ Pre } & \multicolumn{1}{c}{ Post } \\
\hline LSSR & $70.8 \pm 11.3$ & $82.9 \pm 8.2^{* *}, \dagger \dagger$ \\
Sham & $78.9 \pm 11.8$ & $79.6 \pm 12.0$ \\
Control & $76.2 \pm 10.5$ & $76.6 \pm 10.5$ \\
\hline $\mathrm{n}=18$ (mean \pm SD) \\
$* * \mathrm{p}<0.01$ (LSSR vs. sham), $\dagger \dagger \mathrm{p}<0.01$ (LSSR vs. \\
control)
\end{tabular}

Table 1. Changes in ipsilateral SLR (degree)

\begin{tabular}{lll}
\hline & \multicolumn{1}{c}{ Pre } & \multicolumn{1}{c}{ Post } \\
\hline LSSR & $75.4 \pm 9.2$ & $87.4 \pm 9.5^{* *}, \dagger \dagger$ \\
Sham & $78.6 \pm 12.9$ & $80.3 \pm 12.2$ \\
Control & $71.9 \pm 12.3$ & $76.5 \pm 11.9$ \\
\hline $\mathrm{n}=18$ (mean \pm SD) \\
**p $<0.01$ (LSSR vs. sham), $\dagger \dagger \mathrm{p}<0.01$ (LSSR vs. con- \\
trol)
\end{tabular}

Table 3. Changes in lumbar flexion (cm)

\begin{tabular}{lrl}
\hline & \multicolumn{1}{c}{ Pre } & \multicolumn{1}{c}{ Post } \\
\hline LSSR & $2.24 \pm 9.7$ & $5.3 \pm 9.3^{* *}$ \\
Sham & $1.5 \pm 8.2$ & $2.3 \pm 7.6$ \\
\hline $\mathrm{n}=18$ (mean \pm SD) & & \\
$* * \mathrm{p}<0.01$ (LSSR vs. sham) &
\end{tabular}

Table 4. Forces and the magnitude of resultant vector (reliability test) (N)

\begin{tabular}{lcccc}
\hline & $\mathrm{x}$ & $\mathrm{y}$ & $\mathrm{z}$ & Resultant vector \\
\hline Forces & $0.06 \pm 0.29$ & $-5.26 \pm 0.01$ & $6.16 \pm 1.33$ & $8.19 \pm 1.12$ \\
\hline $\mathrm{n}=5$ (mean $\pm \mathrm{SD})$ & & & \\
$\mathrm{x}$ : superior $(-)$; y: caudal $(-)$; $\mathrm{z}$ : ventral $(+)$ & & &
\end{tabular}

The mean value of the applied force in the inferior direction (x-axis) was $0.06 \mathrm{~N}( \pm 0.29 \mathrm{~N})$. In the caudal direction (y-axis), the applied force was $5.26 \mathrm{~N}( \pm 0.01 \mathrm{~N})$. In the ventral direction (z-axis), the applied force was $6.16 \mathrm{~N}( \pm 1.33 \mathrm{~N})$. The mean value of the magnitude of resultant vector was $8.19 \mathrm{~N}( \pm 1.12 \mathrm{~N})($ Table 4$)$.

Both ipsilateral and contralateral SLRs were significantly increased after the LSSR $(p<0.01)$. The difference in the average value of ipsilateral SLR was significantly increased compared to the sham and control groups through multiple comparisons $(\mathrm{F}(2,34)=59.29, \mathrm{p}<0.01)$ (Table 1). The contralateral SLR of the LSSR group was also increased compared to the other 2 groups $(\mathrm{F}(2,34)=18.15, \mathrm{p}<0.01)$ (Table 2$)$. However, there were no significant differences between the sham and control groups. LF was significantly increased after the LSSR $(p<0.01)$. The difference in the average value of LF was also significantly increased compared to the sham group $(F(1,17)=9.04, p<0.01)$ (Table 3$)$.

\section{DISCUSSION}

An applied LSSR force and relative direction were identified with reference to the left side-lying position; in the inferior direction (x-axis) it was $0.06 \mathrm{~N} \pm 0.29 \mathrm{~N}$, in the caudal direction (y-axis) it was $5.26 \mathrm{~N} \pm 0.01 \mathrm{~N}$, and in the ventral direction (z-axis) it was $6.16 \mathrm{~N} \pm 1.33 \mathrm{~N}$. An almost nil force was identified in the superior direction (x-axis), but a force was identified in the caudal, as well as in the ventral direction. That is, the LSSR force was actually applied in the direction of LF. This could be a cause of increased bilateral SLRs and LF due to the LSSR technique.

An identified magnitude of the resultant vector at the $\mathrm{S} 1$ spinous process was $8.19 \mathrm{~N} \pm 1.12 \mathrm{~N}$. This is a remarkably small force compared to the $100 \mathrm{~N}-600 \mathrm{~N}$ of applied force commonly found with joint mobilization and manipulation techniques ${ }^{25}$. The trunk and pelvis were gradually and slowly rotated in opposite directions until the end range was reached in general rotation. Therefore a strong force would not be required in order to rotate the L5-S1 segment just 1-2 degrees ${ }^{26,27)}$. During LSSR, the constant rotation load by the manual force would be expected to produce creep on the soft tissues surrounding the L5-S1 spinous processes such as intervertebral discs, muscles, ligaments, the capsule and articular cartilage of the zygapophysial joint ${ }^{28}$. Gradually, those soft tissues would be stretched. In terms of applying sustained rotation load, viscoelastic properties may be displaced and can be more beneficial than a high speed oscillatory or manipulation technique for obtaining the muscle relaxation and improving the range of motion ${ }^{29)}$. In addition, an applied sustained load would be absorbed into 
those soft tissues during a slow sustained rotation. In contrast, the spinal manipulation technique is performed using a high velocity and low amplitude thrusting force applied to the specific force direction and to a specific joint ${ }^{30)}$. External force (force $\times$ velocity) with the spinal manipulation rotation technique is increased dramatically. In LSSR, the identified $8.19 \mathrm{~N}$ force would confer less stress on the soft tissues and structures at the lumbar segment.

Bilateral SLRs and LF in the LSSR group were significantly increased compared with those of the general rotation group. This could be attributed to be a natural consequence as the segmental sustained rotation was performed immediately after the generalized lumbar rotation. Lumbar intervertebral disc herniation or spondylosis would be affected segmentally ${ }^{1)}$. Therefore, a localized segmental rotation technique might be much more effective than a generalized lumbar rotation when the affected lumbar segment is carefully identified.

There have been no studies of LSSR effects on SLR. However, McFadden and Taylor ${ }^{31)}$ reported that the segmental rotation manipulation was effective for improving SLR and LF. By extrapolation from this study, LSSR as a sustained manner procedure might be effective to improve SLR ${ }^{32)}$. The lumbar nerve roots of healthy adults were stretched $0.5-1.0 \mathrm{~cm}$ with a segmental sustained rotation ${ }^{33}$. The right dorsal nerve root was stretched much more than the right ventral nerve root with the right rotation ${ }^{34)}$. The spinal cord and meninges were elongated in LF and moved anteriorly in the lumbar vertebral canal ${ }^{35)}$. It could be assumed that ipsilateral (right) SLR increased with right LSSR due to the elongation of the nerve root, particularly a right dorsal root. In addition, left side flexion and lumbar flexion might be combined with right LSSR ${ }^{36}$ ). During right LSSR, the right-side neural system (i.e. a nerve root, a dorsal root ganglion, a grey ramus communicant, and a sciatic nerve) as well as the spinal cord and meninges were stretched, and therefore the degree of right SLR was increased ${ }^{37)}$.

As mentioned previously, right rotation, left flexion and forward flexion were combined with right LSSR. Thus, contralateral (left) SLR was increased due to the elongation of the left neural system by LF ${ }^{32}$, however improvement was less than in comparison to ipsilateral SLR.

An instantaneous axis of rotation in flexion and extension at the L5-S1 segment was located at close to the center of the intervertebral disc ${ }^{38}$. Soft tissue structures located posteriorly from the axis of rotation could become a factor of LF limitation $^{36)}$. Those structures include the ligamentum flavum, the intervertebral disc, the joint capsule, the posterior longitudinal ligament, supraspinous and interspinous ligaments, erector spinae muscle and the lumbo dorsal fascia. The orientation of fibers, especially the intervertebral disc, the interspinous ligaments, and the joint capsule, was in the oblique or lateral direction $^{39)}$. Thus, those fibers might be stretched with LSSR. The ligamentum flavum, the posterior longitudinal ligament, the erector spinae muscle, and the lumbo dorsal fascia have a wide cross-sectional area. These fibers could also be stretched towards the direction of rotation, flexion and lateral flexion, which were combined during LSSR. According to the results, LF was increased due to the direction of flexion and the resulting elongation of the soft tissues of the lumbar spine during LSSR.

The study found, with the exception of the $\mathrm{x}$-axis, that the intra-rater reliability for LSSR was excellent, as measured using a measurement system of tri-axial pressure sensors. The identified magnitude of the resultant vector was $8.19 \mathrm{~N}$, which was less than other techniques. Therefore, it can be considered that the LSSR technique is safer than other techniques. The LSSR is effective for improving LF and bilateral SLR. The results suggested that the LSSR can be used for patients with acute lower back pain, or where it is suspected that the nerve root is compromised. The LSSR is useful for improving LF, thus the LSSR can be used to treat spinal canal stenosis when there is limited LF movement ${ }^{40)}$. This measurement system can also be useful for teaching the LSSR technique to physiotherapy students as a tool for providing feedback with regard to applied forces and relative direction.

A sustained rotation technique is often used for patients with suspected nerve root compression and discogenic disorders with unilateral signs and symptoms for the purpose of "opening" the ipsilateral intervertebral foramen (IVF). This presumably affect the "nerve root" of the painful side ${ }^{14)}$. This rotation technique is not a localized lumbar rotation procedure, but a generalized lumbar rotation, although the direction and the sustained manner are similar to the LSSR. However, most of the intervertebral disc herniation could occur posterolaterally $(60 \%)$, often in the intervertebral canal, rather than in the IVF ${ }^{41)}$. Therefore, the S1 nerve root would be predominantly affected in the case of an L5-S1 intervertebral herniation. The reduction of nerve root compression, subsequently improving its signs and symptoms, as found in intervertebral canal herniation, is less dependent upon ipsilateral or contralateral rotation than it is of separating the nerve root and the herniation. In addition, the required applied localized force at the segment could be lower with LSSR than with the generalized lumbar rotation. Consequently, the LSSR technique would be effective for patients with suspected nerve root compression and where careful monitoring of neurological signs and symptoms is essential.

This study has a number of limitations. The study used only 18 subjects, therefore the relatively small sample size is a limitation. Additionally, the subjects were young and healthy with no reported health problems; as such, this would also potentially affect the external validity of the obtained results. Further research would aim to expand the sample size and include patients complaining of lower back pain.

\section{REFERENCES}

1) Maitland GD: Vertebral Manipulation, 5th ed. London: Butterworths; 1986, pp 115-143, 259, 310-313.

2) Van Hoesen LB: Mobilization and manipulation techniques for the lumbar spine. In: Grieve GP (ed.), Modern Manual 
Therapy of the Vertebral Column, 1st ed. Edinburgh: Churchill Livingstone, 1986, pp 733-739.

3) Trott PH, Maitland GD: Manipulative therapy for the low lumbar spine: Technique selection and application to some syndromes. In: Twomey LT, Taylor, (ed.), Physical Therapy of the Low Back. New York: Churchill Livingstone, 1987, pp 199-224.

4) Haswell K: The rotated segment in acute low back pain. J Manual Manip Ther, 1995, 3: 127-134. [CrossRef]

5) Tsung BY, Evans J, Tong P, et al.: Measurement of lumbar spine loads and motions during rotational mobilization. J Manipulative Physiol Ther, 2005, 28: 238-244. [Medline] [CrossRef]

6) Cramer GD, Cambron J, Cantu JA, et al.: Magnetic resonance imaging zygapophyseal joint space changes (gapping) in low back pain patients following spinal manipulation and side-posture positioning: a randomized controlled mechanisms trial with blinding. J Manipulative Physiol Ther, 2013, 36: 203-217. [Medline] [CrossRef]

7) Fazey PJ, Song S, Price RI, et al.: Nucleus pulposus deformation in response to rotation at L1-2 and L4-5. Clin Biomech (Bristol, Avon), 2013, 28: 586-589. [Medline] [CrossRef]

8) Bialosky JE, George SZ, Horn ME, et al.: Spinal manipulative therapy-specific changes in pain sensitivity in individuals with low back pain (NCT01168999). J Pain, 2014, 15: 136-148. [Medline] [CrossRef]

9) Crawford CM, Hannan RF: Management of acute lumbar disk herniation initially presenting as mechanical low back pain. J Manipulative Physiol Ther, 1999, 22: 235-244. [Medline] [CrossRef]

10) Nougarou F, Dugas C, Loranger M, et al.: The role of preload forces in spinal manipulation: experimental investigation of kinematic and electromyographic responses in healthy adults. J Manipulative Physiol Ther, 2014, 37: $287-293$. [Medline] [CrossRef]

11) Sung YB, Lee JH, Park YH: Effects of thoracic mobilization and manipulation on function and mental state in chronic lower back pain. J Phys Ther Sci, 2014, 26: 1711-1714. [Medline] [CrossRef]

12) Bronfort G, Haas M, Evans R, et al.: Evidence-informed management of chronic low back pain with spinal manipulation and mobilization. Spine J, 2008, 8: 213-225. [Medline] [CrossRef]

13) McKenzie RA: The lumbar spine: mechanical diagnosis and therapy. Upper Hutt: Wright \& Carman Limited, 1981.

14) Zito G: Manipulative therapy treatment and its progression in the relief of low back pain. Clinical Proceedings of the Low Back Pain Conference of the Manipulative Therapists Association of Australia (Victoria). Melbourne, 1984, pp 95-113.

15) Gong W: The influence of lumbar joint mobilization on joint position sense in normal adults. J Phys Ther Sci, 2014, 26: 1985-1987. [Medline] [CrossRef]

16) Sato T, Koumori T, Uchiyama Y: Preliminary study of the immediate effect of spinal segmental side bending mobilization on improve lumbar range of motion. J Phys Ther Sci, 2012, 24: 431-434. [CrossRef]

17) Choi J, Hwangbo G, Park J, et al.: The effects of manual therapy using joint mobilization and flexion-distraction techniques on chronic low back pain and disc height. J Phys Ther Sci, 2014, 26: 1259-1262. [Medline] [CrossRef]

18) Park SE, Wang JS: Effect of joint mobilization using KEOMT and PNF on a patient with CLBP and a lumbar transitional vertebra: a case study. J Phys Ther Sci, 2015, 27: 1629-1632. [Medline] [CrossRef]

19) Twomey L, Taylor J: Exercise and spinal manipulation in the treatment of low back pain. Spine, 1995, 20: 615-619. [Medline] [CrossRef]

20) Lee RY: Kinematics of rotational mobilisation of the lumbar spine. Clin Biomech (Bristol, Avon), 2001, 16: 481-488. [Medline] [CrossRef]

21) Mieritz RM, Bronfort G, Jakobsen MD, et al.: Reliability and measurement error of sagittal spinal motion parameters in 220 patients with chronic low back pain using a three-dimensional measurement device. Spine J, 2014, 14: 1835-1843. [Medline] [CrossRef]

22) Doulgeris JJ, Gonzalez-Blohm SA, Aghayev K, et al.: Axial rotation mechanics in a cadaveric lumbar spine model: a biomechanical analysis. Spine J, 2014, 14: 1272-1279. [Medline] [CrossRef]

23) Nwuga VC: Relative therapeutic efficacy of vertebral manipulation and conventional treatment in back pain management. Am J Phys Med, 1982, 61: 273-278. [Medline] [CrossRef]

24) Matyas TA, Bach TM: The reliability of selected techniques in clinical arthrometrics. Aust J Physiother, 1985, 31: 175-199. [Medline] [CrossRef]

25) Willett E, Hebron C, Krouwel O: The initial effects of different rates of lumbar mobilisations on pressure pain thresholds in asymptomatic subjects. Man Ther, 2010, 15: 173-178. [Medline] [CrossRef] 
26) Pearcy MJ, Tibrewal SB: Axial rotation and lateral bending in the normal lumbar spine measured by three-dimensional radiography. Spine, 1984, 9: 582-587. [Medline] [CrossRef]

27) Xia Q, Wang S, Kozanek M, et al.: In-vivo motion characteristics of lumbar vertebrae in sagittal and transverse planes. J Biomech, 2010, 43: 1905-1909. [Medline] [CrossRef]

28) Oliver MJ, Twomey LT: Extension creep in the lumbar spine. Clin Biomech (Bristol, Avon), 1995, 10: 363-368. [Medline] [CrossRef]

29) Lee M, Liversidge K: Posteroanterior stiffness at three locations in the lumbar spine. J Manipulative Physiol Ther, 1994, 17: 511-516. [Medline]

30) Herzog W, Conway PJ, Kawchuk GN, et al.: Forces exerted during spinal manipulative therapy. Spine, 1993, 18: 12061212. [Medline] [CrossRef]

31) McFadden KD, Taylor JR: Axial rotation in the lumbar spine and gaping of the zygapophyseal joints. Spine, 1990, 15: 295-299. [Medline] [CrossRef]

32) Choi J, Lee S, Hwangbo G: Influences of spinal decompression therapy and general traction therapy on the pain, disability, and straight leg raising of patients with intervertebral disc herniation. J Phys Ther Sci, 2015, 27 : $481-483$. [Medline] [CrossRef]

33) Farfan HF: Torsion and compression. In: Mechanical Disorders of Low Back. Philadelphia: Lea \& Febiger, 1973, pp 61-92.

34) Breig A: Adverse mechanical tension in the central nervous system. Stockholm: Almqvist \& Wiksell International, 1978.

35) Troup JD: Biomechanics of the lumbar spinal canal. Clin Biomech (Bristol, Avon), 1986, 1: 31-43. [Medline] [CrossRef]

36) Ebert R, Campbell A, Kemp-Smith K, et al.: Lumbar spine side bending is reduced in end range extension compared to neutral and end range flexion postures. Man Ther, 2014, 19: 114-118. [Medline] [CrossRef]

37) Urban LM: The straight-leg-raising test: a review. In: Grieve GP (ed.), Modern Manual Therapy of the Vertebral Column. Edinburgh: Churchill Livingstone, 1986, pp 567-575.

38) Pearcy MJ, Bogduk N: Instantaneous axes of rotation of the lumbar intervertebral joints. Spine, 1988, 13: $1033-1041$. [Medline] [CrossRef]

39) Izzo R, Guarnieri G, Guglielmi G, et al.: Biomechanics of the spine. Part I: spinal stability. Eur J Radiol, 2013, 82: 118-126. [Medline] [CrossRef]

40) Choi J, Lee S, Jeon C: Effects of flexion-distraction manipulation therapy on pain and disability in patients with lumbar spinal stenosis. J Phys Ther Sci, 2015, 27: 1937-1939. [Medline] [CrossRef]

41) Rowe LT: Imaging of mechanical and degenerative symptoms of the lumbar spine. In: Giles LGF and Singer KP (ed.), The Clinical Anatomy and Management of Back Pain Series. Volume 1: Clinical Anatomy and Management of Low Back Pain. Oxford: Butterworth Heinemann, 1997, pp 276-313. 